\title{
Feature amplified voting algorithm for functional analysis of protein superfamily
}

\author{
Che-Lun Hung ${ }^{1}$, Chihan Lee ${ }^{2}$, Chun-Yuan Lin ${ }^{3}$, Chih-Hung Chang ${ }^{1}$, Yeh-Ching Chung ${ }^{1 *}$, Chuan Yi Tang ${ }^{1}$ \\ From The ISIBM International Joint Conference on Bioinformatics, Systems Biology and Intelligent \\ Computing (IJCBS) \\ Shanghai, China. 3-8 August 2009
}

\begin{abstract}
Background: Identifying the regions associated with protein function is a singularly important task in the postgenomic era. Biological studies often identify functional enzyme residues by amino acid sequences, particularly when related structural information is unavailable. In some cases of protein superfamilies, functional residues are difficult to detect by current alignment tools or evolutionary strategies when phylogenetic relationships do not parallel their protein functions. The solution proposed in this study is Feature Amplified Voting Algorithm with Three-profile alignment (FAVAT). The core concept of FAVAT is to reveal the desired features of a target enzyme or protein by voting on three different property groups aligned by three-profile alignment method. Functional residues of a target protein can then be retrieved by FAVAT analysis. In this study, the amidohydrolase superfamily was an interesting case for verifying the proposed approach because it contains divergent enzymes and proteins.

Results: The FAVAT was used to identify critical residues of mammalian imidase, a member of the amidohydrolase superfamily. Members of this superfamily were first classified by their functional properties and sources of original organisms. After FAVAT analysis, candidate residues were identified and compared to a bacterial hydantoinase in which the crystal structure (1GKQ) has been fully elucidated. One modified lysine, three histidines and one aspartate were found to participate in the coordination of metal ions in the active site. The FAVAT analysis also redressed the misrecognition of metal coordinator Asp57 by the multiple sequence alignment (MSA) method. Several other amino acid residues known to be related to the function or structure of mammalian imidase were also identified.
\end{abstract}

Conclusions: The FAVAT is shown to predict functionally important amino acids in amidohydrolase superfamily. This strategy effectively identifies functionally important residues by analyzing the discrepancy between the sequence and functional properties of related proteins in a superfamily, and it should be applicable to other protein families.

\section{Background}

(The software is freely available for download from reference [1]).

Retrieving useful functional/structural information from a set of amino acid sequences is essential in experimental biological studies. Desired information is often obtainable by analyzing the sequence

\footnotetext{
* Correspondence: ychung@cs.nthu.edu.tw

'Department of Computer Science, National Tsing Hua University, 101,

Section 2 Kuang Fu Road, Hsinchu, Taiwan 300

Full list of author information is available at the end of the article
}

conservations, functional correlations and related structures that belong to a protein/enzyme family or superfamily. An enzyme superfamily is defined as a group of proteins that share the same structural scaffold and that undergo fundamentally similar chemical reactions [2]. Earlier studies [3-5] adopted various pair-wise alignment and multiple sequence alignment (MSA) methods to detect the conserved residues that reveal functional roles in a set of sequences. Classical sequence comparison tools such as FASTA [6], BLAST [3], CLUSTALW [7], T-COFFEE [8] and
C Biomed Central 
MUSCLE [9] can detect similarities in aligned sequences and identify the conserved positions. These positions are essential for further functional analysis. Hierarchical analysis [10-12] is often used to select the most desirable pattern of an alignment. Some protein groups with dissimilar sequences but substantial structural fold similarity (hereinafter referred to as remote homologues) have similar or related biochemical functions [13]. These proteins can be classified into the same superfamily according to their biological properties. Due to their low overall similarity, using alignment methods alone may not reveal the amino acid residues that reflect their physicochemical properties.

In addition to alignment methods, the most common strategy for predicting functional residues from sequences is motif-based sequence analysis [14-17]. However, the motif-based approach often obtains excessive false positives, which limits its use for analyzing a protein superfamily. Phylogenomic techniques such as the evolutionary trace method of identifying functionally important residues [18] use evolutionary information to improve accuracy and are particularly useful for large-scale analyses. This method automatically relates the results back to a given structure and identifies key features structurally clustered around substrate and dimmer interfaces [19-22]. This tool is useful for analyzing protein or enzyme superfamilies and for extracting functional information from enzyme families or superfamilies when the phylogenetic tree or dendrogram approximates a functional distribution.

This study employs a voting concept to search for functional key residues in an enzyme superfamily. Voting or voting-like concepts are widely used in computing algorithms for various purposes. In computational biological applications, voting concepts are often integrated with neural networks for protein clustering and structure prediction [23]. Some theoretical analyses [24-29] indicate that comparing three sequences is better than comparing two sequences because it increases the alignment power needed to distinguish significant matches. Likewise, aligning three groups provides more information than aligning two groups does. Therefore, we developed a Feature Amplified Voting Algorithm with Three-profile alignment (FAVAT) according to the observed sequence similarity and biochemical properties of proteins in the amidohydrolase superfamily. The FAVAT identifies the key residues by calculating a score for each residue in a rat imidase. The functional residues of a rat imidase were identified and further confirmed by experimental references and available structural information.

\section{Results and discussion}

Case study: Imidase-related proteins in amidohydrolase superfamily

In this study, rat imidase was the target sequence, and DRPs (Group II proteins) were classified into $\sim \mathrm{A}$ proteins. Bacterial hydantoinases (Group III enzymes) were classified as A proteins. Although Dihydroorotase, allantoinase and other amidohydrolases (Group IV) were also classified as A proteins, they differ from the Group II enzymes in their functional correlation to target sequence (rat imidase). Following the above classification, the clustered sequences were subjected to FAVAT analysis, and two sets of scores were obtained for each residue of the target sequence. In the experiments, Groups II, III and IV were aligned using the MUSCLE tool adopted by the National Center for Biotechnology Information (NCBI) for protein database alignment.

\section{Voting scores of imidase by FAVAT analysis}

Figure 1 shows the FAVAT analysis results. The T-score suggests the importance of each residue of the target sequence (rat imidase) after accumulating the total voting scores (V-scores), each $\mathrm{V}$-score is calculated from the target sequence, an $\mathrm{A}$ protein sequence and a $\sim \mathrm{A}$ protein sequence. For each rat imidase residue, two sets of T-scores were obtained from the Group II-Group III votes and the Group II-Group IV votes. Ten amino acids (Ala34, His67, His69, Ala134, Lys159, His248, Met297, Arg302, Asp326 and His459) were further analyzed after merging the two sets of the higher T-scores over 60. Table 1 summarizes the amino acid residues selected by FAVAT and MSA analyses and their corresponding locations in two proteins with known crystal structures [PDB:1GKQ, PDB:1KCX].

\section{Comparison of FAVAT and MSA results}

Biologists often use MSA to conjecture important residues of proteins or enzymes of interest among their related sequences. Figure 2 shows the MSA fragments of rat imidase, hamster dihydroorotase domain, yeast allantoinase and Bacillus sp. D-hydantoinase. The MSA analyses revealed that one aspartate and four histidines were highly conserved. The results in Fig. 2 are consistent with data published previously [30-32].

In their studies [30-32], residues Asp57, His59, His61, His 183 and His239 were hypothesized to be critical amino acids for the metal coordinators and function of D-hydantoinase of Thermus sp. Notably, the study [33] reported that a crystal structure of hydantoinase (1GKQ), in which a carboxyl-lysine is responsible for metal binding and is important for enzyme activity, was not revealed by MSA analysis. Another residue, Asp57, which was incorrectly identified as a metal coordinator 
\begin{tabular}{|l|l|l|l|l|l|l|l|l|l|l|l|l|l|l|l|l|l|l|l|l|l|l|l|l|l|l|l|l|l|l|l|l|l|l|l|l|l|l|l|l|}
\hline 1 & M & A & P & Q & E & R & L & L & I & R & G & G & R & V & V & N & D & D & F & S & Q & V & A & D & V & L & V & E & D & G & V & V & $R$ & A & L & G & $R$ & D & L & L \\
\hline
\end{tabular} $\begin{array}{llllllllllllllllllllllllllllllllllllllll}49 & 49 & 49 & 48 & 34 & 29 & 39 & 43 & 47 & 51 & 35 & 37 & 37 & 49 & 48 & 20 & 28 & 32 & 48 & 32 & 58 & 48 & 53 & 47 & 48 & 46 & 50 & 36 & 40 & 46 & 38 & 52 & 45 & 64 & 49 & 34 & 51 & 58 & 40 & 31\end{array}$ $\begin{array}{llllllllllllllllllllllllllllllllllllllllllll}63 & 65 & 60 & 61 & 59 & 37 & 61 & 56 & 58 & 59 & 47 & 48 & 58 & 59 & 53 & 44 & 61 & 42 & 64 & 53 & 75 & 64 & 29 & 53 & 62 & 62 & 80 & 61 & 48 & 52 & 51 & 64 & 56 & 66 & 63 & 49 & 63 & 69 & 53 & 50\end{array}$

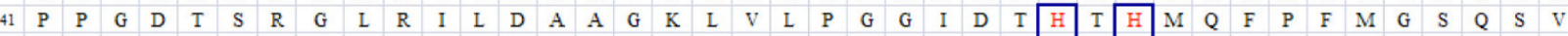
\begin{tabular}{lllllllllllllllllllllllllllll|llllllllllllll}
49 & 40 & 49 & 51 & 0 & 50 & 0 & 35 & 37 & 45 & 56 & 52 & 49 & 31 & 38 & 54 & 44 & 31 & 45 & 46 & 49 & 47 & 39 & 49 & 49 & 44 & 71 & 41 & 78 & 56 & 39 & 53 & 34 & 67 & 56 & 44 & 54 & 49 & 51 & 36
\end{tabular}

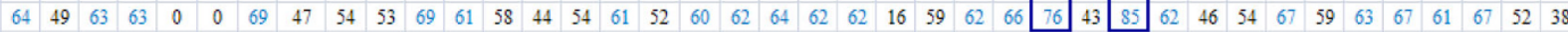

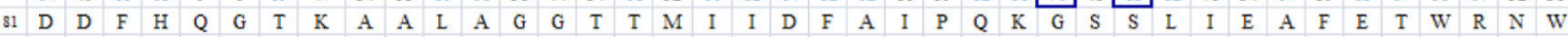
$\begin{array}{lllllllllllllllllllllllllllllllllllllllll}39 & 34 & 46 & 49 & 26 & 40 & 41 & 32 & 34 & 37 & 51 & 48 & 49 & 49 & 42 & 52 & 25 & 42 & 51 & 51 & 86 & 56 & 50 & 30 & 37 & 43 & 38 & 41 & 37 & 40 & 39 & 55 & 52 & 39 & 33 & 58 & 30 & 31 & 57 & 26 & \\ \end{array}$ \begin{tabular}{lllllllllllllllllllllllllllllllllllllllllll}
42 & 44 & 44 & 67 & 62 & 58 & 59 & 50 & 54 & 56 & 59 & 51 & 59 & 61 & 35 & 60 & 38 & 55 & 53 & 54 & 0 & 71 & 60 & 58 & 59 & 57 & 40 & 53 & 36 & 41 & 58 & 49 & 36 & 35 & 57 & 84 & 16 & 46 & 68 & 33 \\
\hline
\end{tabular}

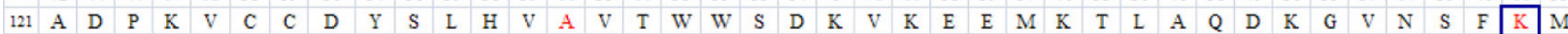
\begin{tabular}{lllllllllllllllllllllllllllllllllllllllllllllll}
36 & 15 & 43 & 41 & 46 & 8 & 2 & 51 & 49 & 41 & 29 & 49 & 40 & 72 & 48 & 43 & 65 & 27 & 58 & 51 & 47 & 47 & 31 & 35 & 39 & 52 & 44 & 30 & 41 & 58 & 49 & 43 & 35 & 46 & 40 & 26 & 43 & 38 & 81 & 42 \\
\hline
\end{tabular} \begin{tabular}{llllllllllllllllllllllllllllllllllllllll}
44 & 40 & 56 & 46 & 58 & 15 & 21 & 49 & 38 & 49 & 43 & 27 & 39 & 69 & 55 & 56 & 51 & 0 & 64 & 52 & 56 & 41 & 47 & 59 & 60 & 61 & 55 & 57 & 43 & 79 & 51 & 46 & 54 & 53 & 57 & 51 & 45 & 46 & 73 & 61 \\
\hline
\end{tabular}

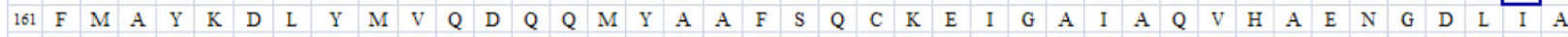
\begin{tabular}{lllllllllllllllllllllllllllllllllllllllllllllll}
50 & 47 & 45 & 44 & 39 & 13 & 55 & 19 & 56 & 58 & 54 & 47 & 51 & 24 & 50 & 23 & 55 & 44 & 40 & 40 & 55 & 50 & 74 & 58 & 35 & 49 & 26 & 40 & 21 & 34 & 48 & 53 & 53 & 47 & 44 & 41 & 43 & 47 & 46 & 23 \\
\hline
\end{tabular} $\begin{array}{lllllllllllllllllllllllllllllllllllllllll}65 & 47 & 30 & 21 & 32 & 29 & 55 & 57 & 62 & 60 & 64 & 45 & 63 & 43 & 62 & 33 & 63 & 78 & 44 & 56 & 69 & 73 & 58 & 64 & 56 & 42 & 25 & 47 & 37 & 55 & 49 & 61 & 38 & 59 & 38 & 32 & 40 & 61 & 45 & 36 & \\ \end{array}$ $\begin{array}{llllllllllllllllllllllllllllllllllllllllllllllll}201 & \text { E } & G & A & K & K & M & \text { L } & \text { A } & \text { L } & \text { G } & \text { I } & \text { T } & G & \text { P } & \text { E } & \text { G } & \text { H } & \text { E } & \text { L } & \text { C } & \text { R } & \text { P } & \text { E } & \text { A } & \text { V } & \text { E } & \text { A } & \text { E } & \text { A } & \text { T } & \text { L } & \text { R } & \text { A } & \text { I } & \text { T } & \text { I } & \text { A } & \text { S } & \text { A } & \text { V }\end{array}$ $\begin{array}{lllllllllllllllllllllllllllllllllllllllllll}37 & 38 & 35 & 44 & 56 & 45 & 32 & 59 & 49 & 49 & 23 & 38 & 33 & 37 & 33 & 23 & 59 & 58 & 49 & 49 & 51 & 49 & 15 & 53 & 50 & 49 & 3 & 48 & 51 & 78 & 52 & 51 & 68 & 46 & 22 & 43 & 42 & 42 & 53 & 53\end{array}$ $\begin{array}{llllllllllllllllllllllllllllllllllllllllllll}50 & 69 & 53 & 47 & 53 & 49 & 33 & 64 & 52 & 58 & 57 & 58 & 44 & 32 & 41 & 28 & 43 & 51 & 45 & 62 & 51 & 46 & 37 & 66 & 55 & 60 & 25 & 45 & 41 & 58 & 75 & 53 & 40 & 54 & 40 & 53 & 45 & 56 & 67 & 57\end{array}$

\begin{tabular}{lllllllll|llllllllllllllllllllllllllllllllllllllllllllll}
241 & N & C & P & L & Y & I & V & H & V & M & S & K & S & A & A & K & V & I & A & D & A & K & R & E & G & K & V & V & Y & G & E & P & I & A & A & G & L & G & T & D
\end{tabular}

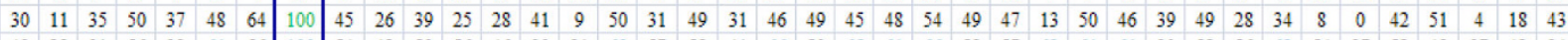
$\begin{array}{lllllllllllllllllllllllllllllllllllllllllllllll}43 & 29 & 31 & 56 & 39 & 61 & 56 & 100 & 54 & 42 & 50 & 56 & 46 & 30 & 31 & 69 & 57 & 58 & 41 & 66 & 50 & 65 & 61 & 66 & 59 & 57 & 62 & 61 & 61 & 30 & 58 & 56 & 62 & 54 & 37 & 52 & 48 & 37 & 42 & 34\end{array}$

$\begin{array}{llllllllllllllllllllllllllllllllllllllllllllllllllllll}281 & G & \text { T } & \text { Q } & \text { Y } & \text { W } & \text { N } & \text { K } & \text { E } & \text { W } & \text { R } & \text { H } & \text { A } & \text { A } & \text { H } & \text { H } & \text { V } & \text { M } & \text { G } & \text { P } & \text { P } & \text { L } & \text { R } & \text { P } & \text { D } & \text { P } & \text { S } & \text { T } & \text { P } & \text { G } & \text { F } & \text { L } & \text { M } & \text { N } & \text { L } & \text { L } & \text { A } & \text { N } & \text { G } & \text { D } & \text { L }\end{array}$ \begin{tabular}{llllllllllllllllllllllllllllllllllllllllllllll}
1 & 42 & 41 & 35 & 14 & 52 & 31 & 59 & 11 & 41 & 40 & 25 & 23 & 20 & 52 & 45 & 74 & 56 & 53 & 49 & 32 & 77 & 34 & 14 & 9 & 38 & 9 & 8 & 61 & 32 & 15 & 43 & 61 & 48 & 22 & 26 & 50 & 56 & 13 & 43 \\
\hline
\end{tabular} $\begin{array}{llllllllllllllllllllllllllllllllllllllllllllllllll}24 & 47 & 53 & 33 & 12 & 62 & 60 & 73 & 2 & 38 & 54 & 22 & 42 & 40 & 61 & 32 & 74 & 65 & 62 & 55 & 60 & 80 & 37 & 61 & 38 & 60 & 34 & 29 & 62 & 55 & 61 & 62 & 61 & 37 & 56 & 49 & 69 & 65 & 40 & 51\end{array}$

$\begin{array}{lllllllllllllllllllllllllllllllllllllllllllllll}321 & \text { T } & \text { T } & \text { T } & G & \text { S } & \text { D } & \text { N } & \text { C } & \text { T } & \text { F } & \text { N } & \text { T } & \text { C } & \text { Q } & \text { K } & \text { A } & \text { L } & \text { G } & \text { K } & \text { D } & \text { D } & \text { F } & \text { T } & \text { K } & \text { I } & \text { P } & \text { N } & \text { G } & \text { V } & \text { N } & \text { G } & \text { V } & \text { E } & \text { D } & R & \text { M } & \text { S } & \text { V } & \text { I } & \text { W }\end{array}$ \begin{tabular}{llllll|llllllllllllllllllllllllllllllllllllllllll}
57 & 54 & 37 & 49 & 40 & 68 & 47 & 48 & 49 & 47 & 43 & 35 & 40 & 38 & 45 & 27 & 44 & 42 & 19 & 31 & 66 & 42 & 28 & 58 & 49 & 45 & 79 & 51 & 48 & 31 & 43 & 46 & 49 & 45 & 41 & 41 & 32 & 37 & 44 & 18
\end{tabular}

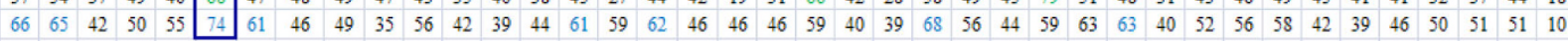

\begin{tabular}{ll|llllllllllllllllllllllllllllllllllllllllllll}
361 & E & K & G & V & H & S & G & K & M & D & E & N & R & F & V & A & V & T & S & T & N & A & A & K & I & F & N & L & Y & P & K & K & G & R & I & A & V & G & S & D
\end{tabular} $\begin{array}{lllllllllllllllllllllllllllllllllllllllllllll}36 & 31 & 46 & 47 & 44 & 48 & 46 & 33 & 32 & 14 & 16 & 28 & 43 & 37 & 49 & 16 & 42 & 35 & 42 & 43 & 34 & 3 & 48 & 47 & 48 & 44 & 34 & 47 & 35 & 41 & 50 & 46 & 43 & 26 & 43 & 23 & 40 & 49 & 41 & 47\end{array}$ $\begin{array}{llllllllllllllllllllllllllllllllllllllllllllllll}51 & 53 & 41 & 56 & 58 & 57 & 46 & 39 & 50 & 34 & 28 & 39 & 53 & 38 & 50 & 29 & 42 & 40 & 51 & 45 & 52 & 20 & 51 & 47 & 55 & 58 & 38 & 62 & 57 & 44 & 55 & 51 & 61 & 48 & 56 & 56 & 49 & 56 & 47 & 41\end{array}$

$\begin{array}{lllllllllllllllllllllllllllllllllllllllllllllllllll}401 & \text { A } & \text { D } & \text { M } & \text { V } & \text { I } & \text { W } & \text { D } & \text { P } & \text { E } & \text { A } & \text { T } & \text { R } & \text { T } & \text { I } & \text { S } & \text { A } & \text { K } & \text { T } & \text { H } & \text { H } & \text { Q } & \text { A } & \text { V } & \text { N } & \text { F } & \text { N } & \text { I } & \text { F } & \text { E } & \text { G } & \text { M } & \text { V } & \text { C } & \text { H } & \text { G } & \text { V } & \text { P } & \text { L } & \text { V } & \text { T }\end{array}$ $\begin{array}{llllllllllllllllllllllllllllllllllllllllllll}49 & 49 & 49 & 44 & 47 & 8 & 41 & 37 & 50 & 28 & 44 & 40 & 38 & 44 & 44 & 29 & 43 & 48 & 28 & 57 & 50 & 43 & 44 & 55 & 44 & 38 & 33 & 46 & 48 & 55 & 29 & 51 & 0 & 13 & 45 & 44 & 34 & 21 & 26 & 50\end{array}$ $\begin{array}{llllllllllllllllllllllllllllllllllllllllllllll}59 & 54 & 61 & 53 & 56 & 2 & 60 & 34 & 62 & 52 & 62 & 50 & 55 & 58 & 50 & 36 & 48 & 51 & 26 & 65 & 63 & 45 & 52 & 66 & 61 & 35 & 39 & 57 & 43 & 64 & 42 & 68 & 34 & 38 & 54 & 49 & 35 & 50 & 42 & 77\end{array}$

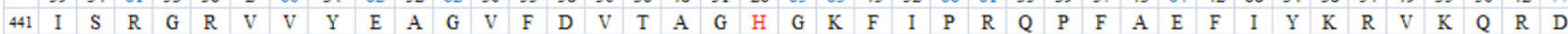
$\begin{array}{llllllllllllllllllllllllllllllllllllllllll}44 & 35 & 56 & 48 & 39 & 45 & 43 & 54 & 39 & 51 & 32 & 48 & 45 & 44 & 36 & 19 & 45 & 34 & 61 & 49 & 52 & 34 & 43 & 1 & 56 & 49 & 41 & 37 & 55 & 0 & 51 & 41 & 21 & 38 & 31 & 42 & 38 & 39 & 26 & 52 & \\ \end{array}$ $\begin{array}{lllllllllllllllllllllllllllllllllllllllllll}53 & 43 & 66 & 60 & 55 & 56 & 60 & 71 & 47 & 68 & 41 & 60 & 56 & 62 & 52 & 48 & 63 & 49 & 63 & 55 & 57 & 47 & 60 & 45 & 59 & 61 & 51 & 49 & 67 & 59 & 59 & 60 & 57 & 60 & 59 & 59 & 60 & 60 & 60 & 60\end{array}$

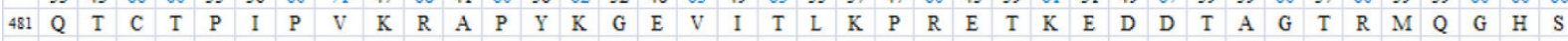
$\begin{array}{lllllllllllllllllllllllllllllllllllllllll}57 & 53 & 41 & 59 & 60 & 0 & 0 & 0 & 52 & 0 & 0 & 0 & 0 & 0 & 0 & 0 & 0 & 0 & 0 & 52 & 52 & 38 & 40 & 44 & 38 & 46 & 55 & 30 & 36 & 47 & 41 & 42 & 56 & 43 & 45 & 52 & 48 & 50 & 49\end{array}$ $\begin{array}{lllllllllllllllllllllllllllllllllllllllllllllll}63 & 63 & 61 & 64 & 63 & 64 & 63 & 61 & 62 & 61 & 62 & 63 & 60 & 63 & 61 & 62 & 61 & 62 & 62 & 61 & 62 & 62 & 63 & 62 & 61 & 62 & 62 & 62 & 62 & 63 & 62 & 63 & 62 & 62 & 62 & 62 & 63 & 63 & 62\end{array}$

Figure 1 Total voting scores (T-scores) of rat imidase by FAVAT analysis The scores were obtained by voting algorithm as described in Methods. The first row is the rat imidase sequence. The scores in the second and third rows are accumulated V-scores (T-score) for the Group IIGroup III and Group II-Group IV votes, respectively. Amino acid residues are marked in red if both votes resulted in T-scores over 60 . The T-scores over 60 for Group II-Group III and Group II-Group IV votes appear in green and blue, respectively. The boxed residues indicate the residues corresponding to metal coordination in bacterial hydantoinase (1GKQ).

Table 1 Functional annotations of the residues in rat imidase selected by FAVAT

\begin{tabular}{|c|c|c|c|c|c|}
\hline $\begin{array}{l}\text { FAVAT score } \\
\text { ranking }\end{array}$ & $\begin{array}{l}\text { FAVAT selected } \\
\text { residues }\end{array}$ & $\begin{array}{l}\text { Corresponding residues } \\
\text { in } 1 \mathrm{GKQ}^{1}\end{array}$ & $\begin{array}{l}\text { Corresponding residues } \\
\text { in } 1 \mathrm{KCX}^{1}\end{array}$ & $\begin{array}{l}\text { MSA predicted } \\
\text { residues }^{2}\end{array}$ & $\begin{array}{l}\text { Functional annotation base } \\
\text { on } 1 \mathrm{GKQ}\end{array}$ \\
\hline 1 & His248 & His239 & Lys254 & His239 & Metal coordinate \\
\hline 2 & His69 & His61 & Tyr75 & His61 & Metal coordinate \\
\hline 3 & Arg302 & Arg292 & Ser308 & & Conformation \\
\hline 4 & Lys159 & Lys150 (Kcx) & Gln165 & & Metal coordinate \\
\hline 5 & Met297 & Met287 & Thr303 & & Conformation \\
\hline 6 & His67 & His59 & Asn73 & His59 & Metal coordinate \\
\hline 7 & Asp326 & Asp315 & Gly332 & & Metal coordinate \\
\hline 8 & Ala134 & Ala126 & Asp139 & & $\begin{array}{l}\text { Secondary structure core } \\
\text { residue }\end{array}$ \\
\hline 9 & Ala34 & $\operatorname{Arg} 30$ & $\mathrm{Gln} 44$ & & Quaternary structure \\
\hline 10 & His459 & Trp448 & Met465 & & Quaternary structure \\
\hline
\end{tabular}

${ }^{1} \mathrm{GKQ}$ and $1 \mathrm{KCX}$ are the structure IDs of D-hydantoinase and collapsin response mediator proteins (CRMPs), respectively.

${ }^{2}$ MSA result according to the manuscript [66]. 


\begin{tabular}{|c|c|c|c|}
\hline & Frame 1 & Frame 2 & Frame 3 \\
\hline DHP & 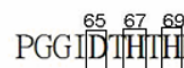 & AQV $\stackrel{192}{H} A E N G D L$ & $\begin{array}{c}248 \\
\text { IVHNMS }\end{array}$ \\
\hline DHO & PGLIDVHMH & IVAHAERQSV & PHHLFL \\
\hline DAL & PGLVDSHMH & MMFHAELPKA & PVHIVH \\
\hline HYD & PGGIDPHIH & VMVHAENGDV & VVHNSC \\
\hline \multicolumn{4}{|c|}{$\begin{array}{l}\text { Figure } 2 \text { Results of MSA analysis A multiple sequence alignment } \\
\text { of imidase (DHP), dihydroorotase (DHO), allantoinase (DAL) and D- } \\
\text { hydantoinase (HYD) was performed using CLUSTALW. The } \\
\text { conserved amino acid residues among the four enzymes are shown } \\
\text { in bold type and enclosed in rectangles. }\end{array}$} \\
\hline
\end{tabular}

in a previous study that applied MSA method as the corresponding residue in $1 \mathrm{GKQ}$, revealed no involvement in metal coordination. Table 1 shows that, in the current study, FAVAT successfully identified all known important residues in rat imidase. The Lys159, His67, His69, His248 and Asp326, which correspond to Lys150, His59, His61, His239 and Asp315 in hydantoinase
(1GKQ), are metal ion coordinators (boxed amino acids in Fig. 3).

\section{The corresponding locations of FAVAT-selected residues in $1 \mathrm{GKQ}$ and $1 \mathrm{KCX}$}

The possible functions of imidase amino acids selected by FAVAT were further analyzed using 1GKQ and $1 \mathrm{KCX}$, which are known structures of imidase related proteins. The former is the crystal structure of a Dhydantoinase that represents an A protein (Group III) in FAVAT analysis. The latter is the crystal structure of a dihydropyrimidinase-related protein (CRMP1) that represents a $\sim$ A protein (Group II) in FAVAT analysis. Figure 3 shows their corresponding sequences and secondary structures. The similar $\beta / \alpha$ core structures were observed in the wiring diagrams of $1 \mathrm{GKQ}$ and $1 \mathrm{KCX}$. The significant difference in these structures is that 1 GKQ forms a typical $(\beta / \alpha)_{8}$ domain, but $1 \mathrm{KCX}$ does not. The FAVAT-selected amino acids may reflect both the structure feature and metal requirement that are responsible for the different functions of the $\mathrm{A}$ and

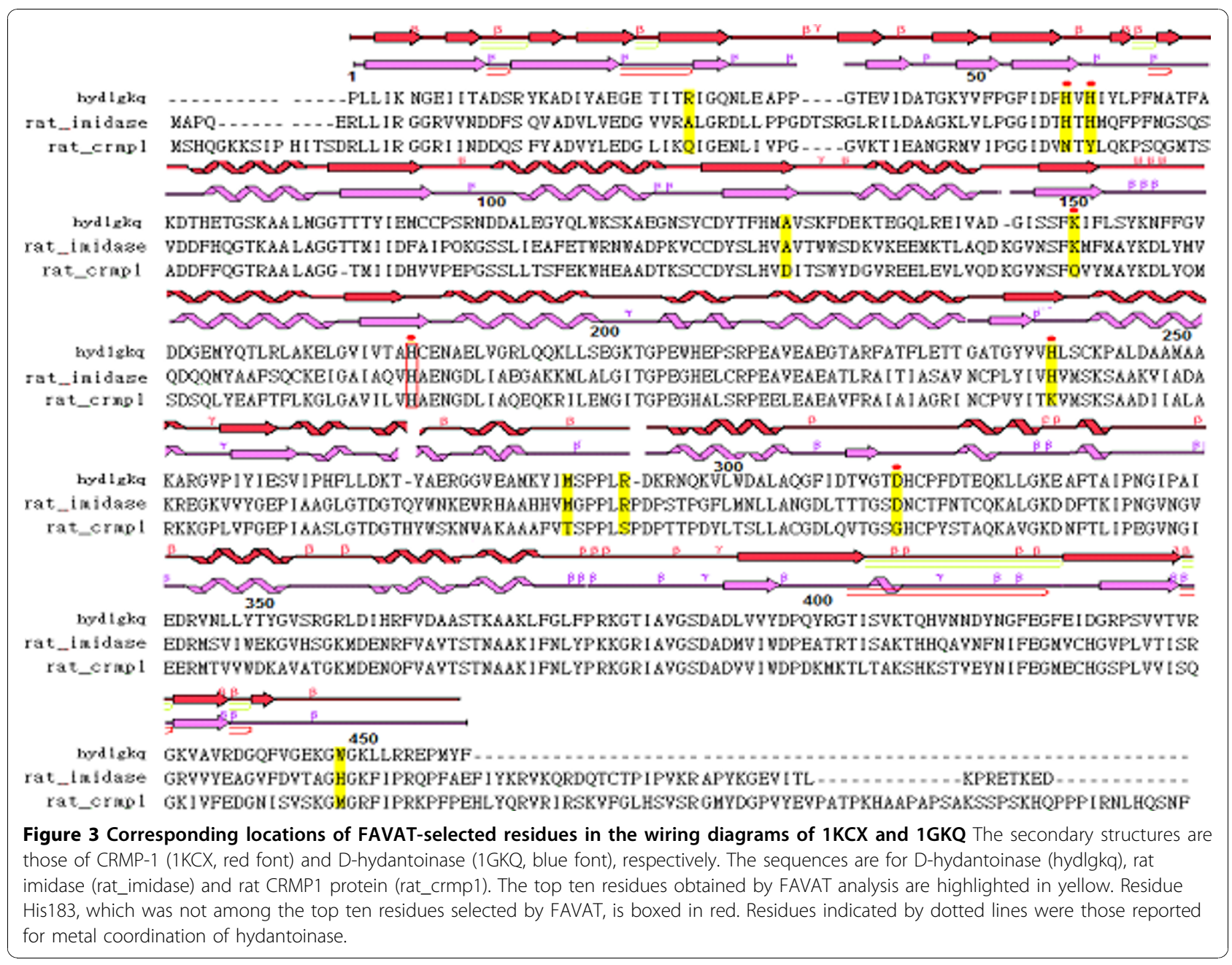




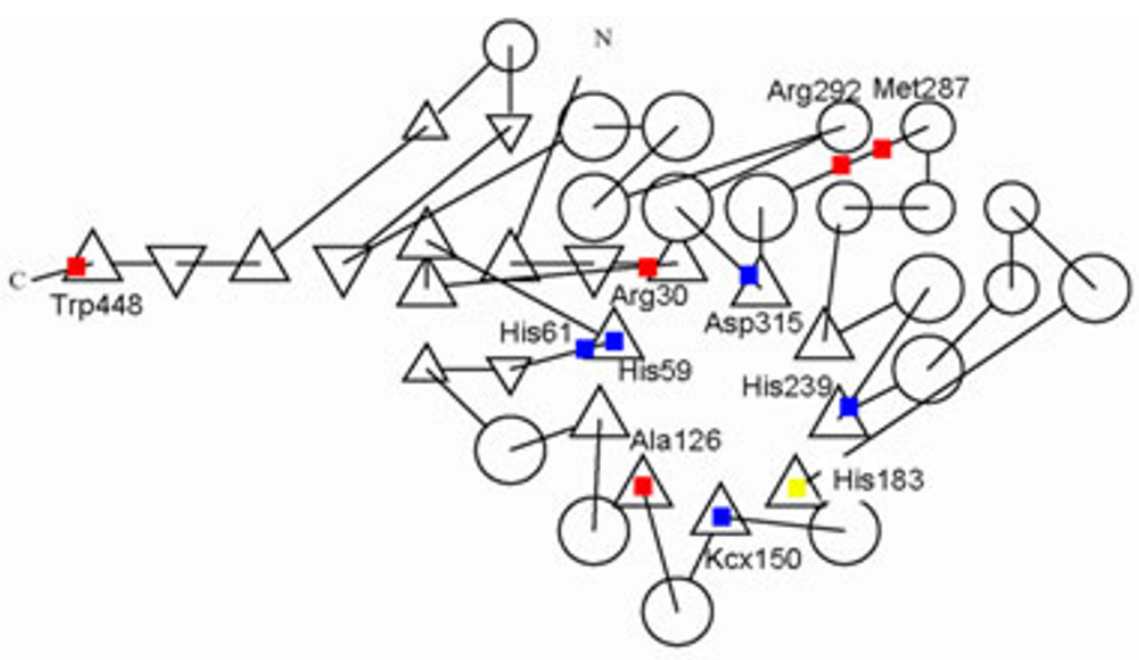

(a)

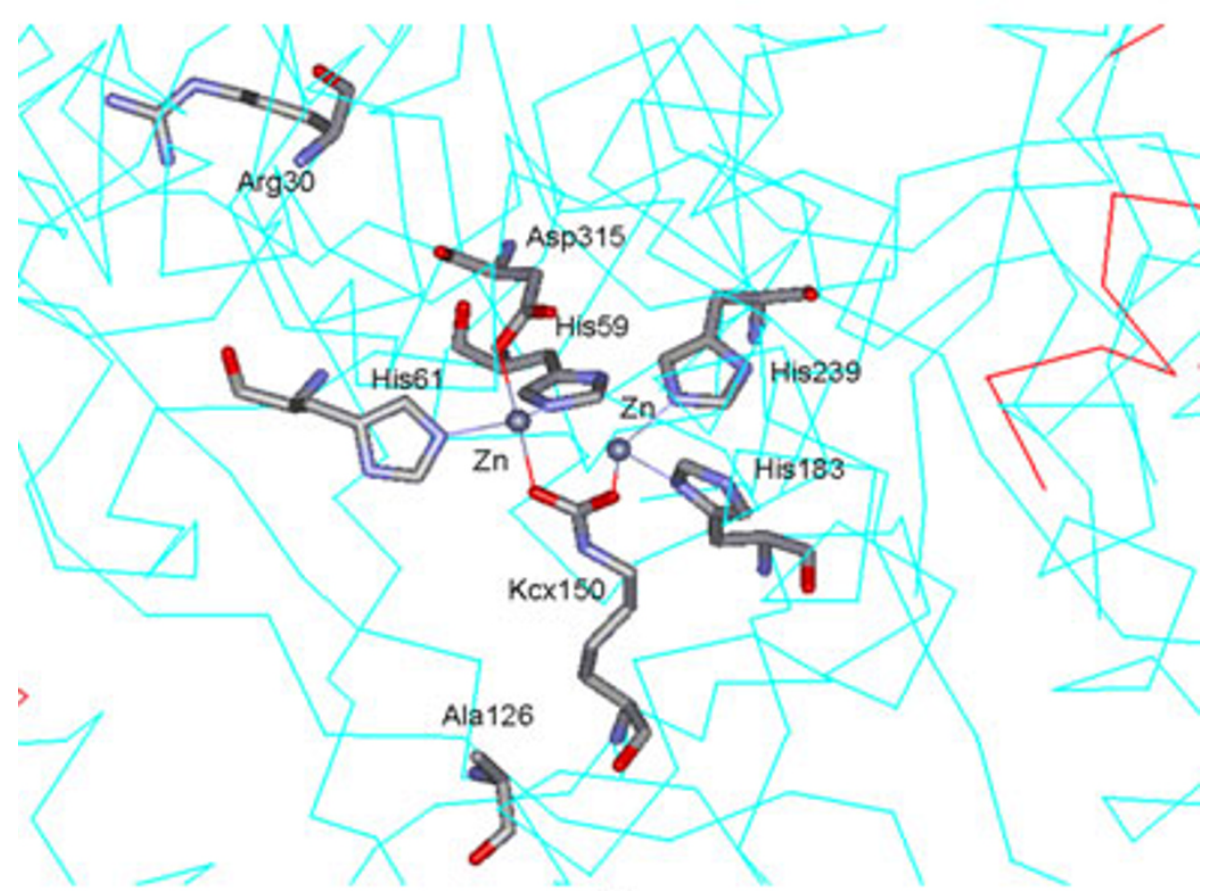

(b)

Figure 4 Corresponding locations of amino acid residues identified by FAVAT in 1GKQ (a) The top ten residues selected by FAVAT on the topology of 1GKQ. Carboxylated lysine residue (Kcx150), His59, His61, His239 and Asp315 that were involved in metal coordination are indicated by blue font. Residue His183 (yellow font) was not identified in this study. Other selected residues are indicated by red font. (b) The metal binding site of $1 \mathrm{GKQ}$. The corresponding amino acids identified by FAVAT are highlighted.

$\sim \mathrm{A}$ proteins. The corresponding locations of Ala34 and His459 in 1GKQ (Arg30 and Trp448 in the N-terminal and $\mathrm{C}$-terminal $\beta$-Sheet, respectively) and in $1 \mathrm{KCX}$ (Gln44 and Met465 in the N-terminal and C-terminal $\beta$-Sheet, respectively) were domains in which they interact with another monomer to form a quaternary structure in both hydantoinase and CRMP1 $[34,35]$. Residues His67, His69, Ala134, Lys159, His248 and Asp326 (His59, His61, Ala126, Kcx150, His239 and Asp315 in 1GKQ; His73, Tyr75, Asp139, Gln165, 
Lys 254 and Gly332 in 1 KCX) are located in the $\beta / \alpha$ core region.

Figure 4a is a topological view of the corresponding FAVAT-selected amino acids in 1GKQ. Thermus sp. Dhydantoinase (1GKQ) contains two divalent metal ions in active site (Fig. $4 \mathrm{~b}$ ). The central binuclear zinc center is bridged by the carboxylated lysine residue (Kcx150) and a hydroxide ion. Residues His59, His61, His183, His239 and Asp315 correspond to the active site zinc ion (Fig. 4b). The corresponding residues were conserved in other members of the amidohydrolase superfamily [36,37]. However, in CRMP1, four of the five corresponding residues are diverse [38]. These residues were all identified by FAVAT analysis. Other candidates recognized by FAVAT analysis, Ala134, Arg302, Ala34, Met297 and His459, were also found to reside in positions critical to protein function. The corresponding residue of Ala134 in 1GKQ (Ala126), was located near the active site (Fig. 4b). Residues Arg302 and Met297 (Arg292 and Met287 in 1GKQ, respectively) were located at the helix-loop domain outside the $(\beta / \alpha)_{8}$ catalytic domain. This implies that they may be important for maintaining structure or stabilizing the protein conformation (Fig. 4a). These preliminary findings merit further detailed study.

Although the metal coordinators of imide-hydrolyzing enzymes in this case study were dispersed sequentially, almost all the known metal coordinators in 1GKQ were identified by FAVAT except His 183 (His 192 for rat imidase). This residue is conserved in CRMP1 but lacks metal and amidohydrolytic activity. The role of this histidine needs further study. The major difference between bacterial hydantoinase and mammalian imidase is their metal content. The former contains two metal ions while the later contains only one metal ion $[39,40]$. Fewer metal coordinators may be needed for mammalian imidase, and residue His 192 may not be required as a coordinator of metal ions in rat imidase. A mammalian imidase was crystallized recently [41]. The difference between mammalian imidase and non-mammalian imidase is expected to be clarified in the near future.

\section{Conclusions}

The FAVAT was developed to predict functionally important amino acids in mammalian imidase. A Tscore was given to each residue of the target enzyme by analyzing imidase-related proteins in the amidohydrolase superfamily on the basis of their sequence-function relationships. Of the ten top T-score amino acids selected, six (His67, His69, Lys159, His192, His248 and Asp326) corresponded to metal coordination in D-hydantoinase. The other four amino acids corresponded with positions that were structurally important for forming quaternary structures and secondary structures in 1GKQ. Residue
Asp57, which was misrecognized as a metal coordinator in previous MSA analyses, was correctly recognized by FAVAT. This study showed that analyzing the discrepancy between the sequence and functional properties of related proteins in a superfamily is an effective method of identifying functionally important residues. This strategy should be applicable to other protein families, and the authors expect to employ this strategy for analyzing critical residues of viruses in future works.

\section{Methods}

Imidase and sequence clustering in the amidohydrolase superfamily

Hydantoinase activity was first reported in plants and animals $[42,43]$ to hydrolyze hydantoin derivatives that are not known as physiological metabolites. This enzymatic activity is useful for preparing optically pure amino acids that are precursors for various antibiotics [44]. Due to its industrial application, several hydantoinases have been studied and purified from microorganisms $[45,46]$. A dihydropyrimidinase $(5,6$ dihydropyrimidine amidohydrolase) partially purified from animal livers was shown to hydrolyze the physiological substrate dihydropyrimidine [47]. A detailed study of a homogenous imide-hydrolyzing enzyme, imidase, which was purified from rat, pig or fish livers [48-51], revealed that it catalyzes a wide spectrum of substrates, including dihydropyrimidines, hydantoins and other imides [52]. Despite the substrate spectra of hydantoinase highly similar to imidase, these imide-hydrolyzing enzymes from bacterial and mammalian sources reportedly have relatively low sequence similarity. Some mammals, flies and C. elegans, reveal proteins with high sequence similarity to dihydropyrimidinase (or imidase). These dihydropyrimidinase-related proteins (DRPs) may be involved in cancer and neuron cells development, but possess no imidase activity [53-55]. Additionally, other enzymes revealed by the studies in evolution of the metabolic pathway are also known to use mechanisms similar to those observed in imidase $[56,57]$. These enzymes include dihydroorotase, allantoinase, urease and amidohydrolases, which originate in mammals, plants and fungi [58]. All use distinct substrates that contain similar imide functional groups.

All of the above enzymes can be classified into the amidohydrolase superfamily according to their properties and structures [59]. In this superfamily, some proteins have similar sequences but divergent functions whereas others have similar functions but low sequence similarity. This phenomenon strongly suggests that only a few critical amino acid residues in this superfamily are needed for specific protein functions. Proteins in the amidohydrolase superfamily can be grouped according to their sequence similarity and biochemical properties, 
and an effective strategy for analyzing these proteins may yield valuable information.

A string search containing the rat imidase sequence (Accession No.: NP_113893) yielded 156 protein sequences of amidohydrolase superfamily were obtained from the PIR database [60]. According to their sequence similarity and functional properties, sequences were further clustered into the following five groups (Table 2): I. imidase (imide-hydrolyzing enzyme from mammal); II. sequence-related proteins (dihydropyrimidinase-related proteins with $50 \%$ or higher sequence similarity to mammalian imidase but without imidase activity); III. functionally identical enzymes (hydantoinase, or the imide-hydrolyzing enzyme from bacteria with 30-40\% sequence similarity to mammalian imidase); IV. functionally-related enzymes (dihydroorotase, allantoinase, urease and amidohydrolase with $25-48 \%$ sequence similarity to mammalian imidase); and V. putative sequences (gene products with unknown function) with $30 \%$ or higher sequence similarity to mammalian imidase.

\section{Observation and assumption}

Table 2 shows the significant findings of the comparisons of sequence identity and functional properties of the imidase-related proteins in the amidohydrolase superfamily. Sequence-related proteins (Group II) had no imidase activity even though the overall similarity of sequences in this group was higher than 50\% [61]. This phenomenon implicated that key amino acid residues for imidase activity have been altered or removed from Group II proteins. In contrast, functionally identical and functionally related enzymes (Group III and Group IV, respectively) had lower sequence identity, but they basically catalyzed the same reaction. For these enzymes, few conserved residues should be needed to provide a similar imidase function. The above observation implies a principle for classifying the sequence or the functional divergent enzymes in a superfamily, which may help to develop a feature amplified voting algorithm for identifying key residues in a target protein. Biologists generally select a sequence of interest as a target and perform BLAST analysis to recover related protein sequences. By definition, a specific function or property (e.g., substrate specificity) of a sequence of interest can be used to cluster the related sequences into different groups. For example, if property A is used to classify these sequences, sequences with property A should be classified into group A. Otherwise, the sequence should be classified into group $\sim$ A. Based on the classification of these three groups, a critical assumption can be made. When the target sequence, the A sequence and the $\sim \mathrm{A}$ sequence belong to a protein superfamily, the conserved residues of the target sequence and the A sequence should correlate to property A. However, the non-conserved residues of the target sequence and $\sim \mathrm{A}$ sequence should also reflect the negative correlation in property $A$. The intersection of the residues provides important functional clues. Thus, important residues can be found by comparing these three property groups. Therefore, the three-profile alignment method was developed to optimize the alignment of three groups so that key residues are then revealed by voting algorithm. Figure 5 shows the FAVAT flowchart that was developed to retrieve useful information for these distinct groups. Analysis of the imidase-related sequences in Table 2 indicated that, within this superfamily, the degree of sequence similarity did not necessarily reflect the similarity in biochemical properties. This provides a good opportunity to develop a novel method for extracting functional residues of a target enzyme. In this work, FAVAT was used to examine each residue in mammalian imidase by comparing other sequences in the amidohydrolase superfamily. Given the limited structural information about mammalian imidase, the analytical results of this study should provide important clues for enzymologists to perform further in-depth biochemical analyses of these results.

Table 2 Grouping of imidase related proteins ${ }^{1}$

\begin{tabular}{|c|c|c|c|}
\hline Group & Member number & Sequence identity & Imidase Activity \\
\hline I. Imidase (target enzyme) & 5 & $98-100 \%$ & Yes \\
\hline II. Sequence related proteins ${ }^{2}$ & 43 & $50-80 \%$ & No \\
\hline III. Functionally identical enzymes ${ }^{3}$ & 16 & $30-40 \%$ & Yes \\
\hline IV. Functionally related enzymes ${ }^{4}$ & 63 & $25-48 \%$ & Yes \\
\hline V. Putative proteins ${ }^{5}$ & 29 & $30-60 \%$ & Unknown \\
\hline
\end{tabular}

${ }^{1}$ Proteins are grouped according to properties related to the target enzyme (rat imidase).

${ }^{2}$ Sequence-related proteins, referred to as dihydropyrimidinase related proteins (DRPs), with no imidase activity.

${ }^{3}$ Functionally identical enzymes, referred to as bacterial imide-hydrolyzing enzyme or hydantoinase, in which substrate spectrums were virtually identical to that of the target enzyme.

${ }^{4}$ Functionally-related enzymes, including dihydroorotase, allantoinase, and urease. Each enzyme catalyzes its own distinct substrate that contains an imide functional group.

${ }^{5}$ Putative proteins are referred to as gene products with unknown function. 


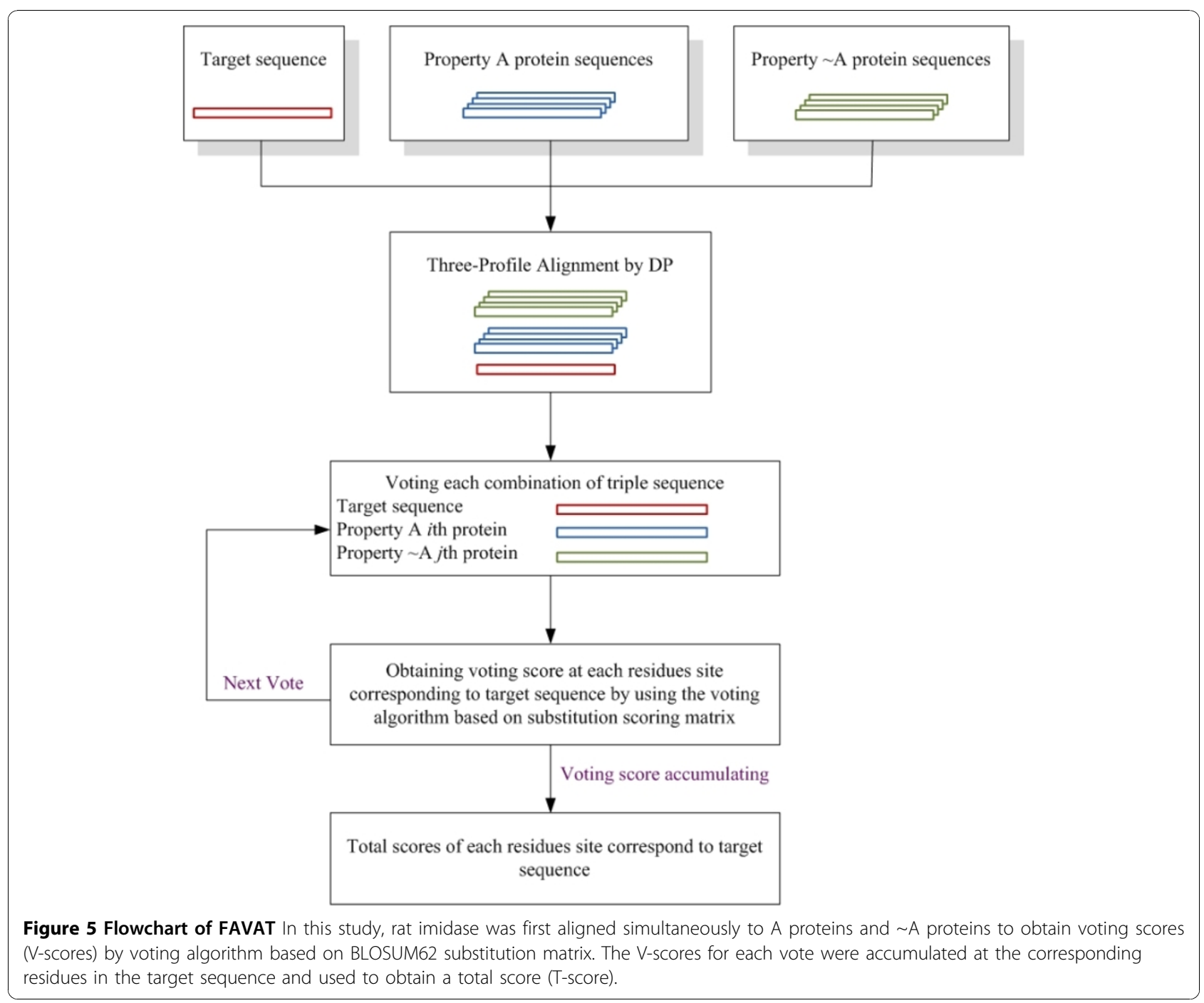

\section{Algorithm}

The FAVAT was performed in two steps. The first step was to align the target enzyme, functionally identical enzymes (A proteins) and sequence-related proteins $(\sim \mathrm{A}$ proteins) using three-profile alignment. The three-profile alignment algorithm, which is based on the dynamic programming three-way alignment approach $[62,63]$, was designed to align three profiles in a space. As in the FAVAT pre-process, each profile can be generated by multiple sequence alignment tools such as T-COFFEE, HMMER [64] and MUSCLE.

Let $P_{1}, P_{2}$ and $P_{3}$ be three profiles, and $P_{1 i}, P_{2 j}$ and $P_{3 k}$ refer to the $i$ th, $j$ th and $k$ th positions in $P_{1}, P_{2}$ and $P_{3}$, respectively, starting from 1 . The symbol "-" denotes a "gap" in the alignment. Scores for the alignment of two columns are denoted by $S p(\alpha, \beta)$. The scoring pair profiles $P_{1}-P_{2}$ are defined as follows:

$$
S p_{12}(i, j)=\frac{\sum_{a=1}^{m} \sum_{b=1}^{n}\left(W_{a} \times W_{b} \times M\left[r_{1(a, i)}\right]\left[r_{2(b, j)}\right]\right)}{m \times n}
$$

where $S p_{12}$ is the score at the $i$ th andjth columns on $P_{1}$ and $P_{2}$, respectively. The $P_{1}$ has $m$ sequences, and $P_{2}$ has $n$ sequences. The $W_{a}$ and $W_{b}$ are the sequence weights for sequence $a$ in $P_{1}$ and sequence $b$ in $P_{2}$, respectively. The residue at ith column for sequence $a$ in $P_{1}$ is denoted by $r_{1(a, i)}$. The $M$ is the value of the substitute matrix for $r_{1(a, i)}$ and $r_{2(b, j)}$. Many substitution matrices, such as BLOSUM, have been proposed to improve alignment accuracy [65]. Similarly, the definitions of scoring pair profiles $P_{1}-P_{3}$ and $P_{2}-P_{3}$ are similar to those of pair profile $P_{1}-P_{2}$. Gap penalties are determined by gap opening (GOP) and gap extension (GEP) 


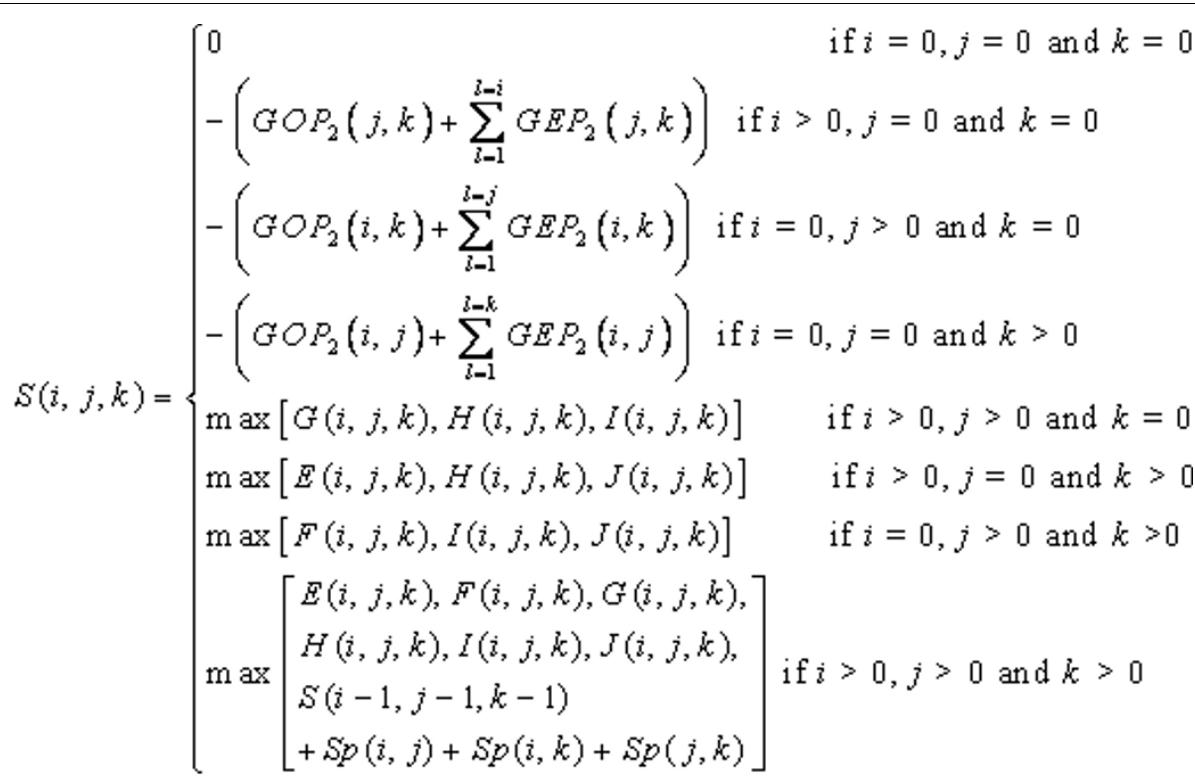

$$
\begin{aligned}
& G(i, j, k)=\max \left\{\begin{array}{l}
S_{(i-1, j-L k)}-G O P_{1}(k), \\
G_{(i-1, j-1 k)}
\end{array}\right\}+S p(i, j)-G E P_{1}(k) \text { if } i>0, j>0 \\
& E(i, j, k)=\max \left\{\begin{array}{l}
S_{\langle i-1, k-1)}-G O P_{1}(j), \\
E_{(i-1, j, k-1)}
\end{array}\right\}+S p(i, k)-G E P_{1}(j) \text { if } i>0, k>0 \\
& F(i, j, k)=\max \left\{\begin{array}{l}
S_{(i, j-1, k-1)}-G O P_{1}(i), \\
F_{(i, j-1, k-1)}
\end{array}\right\}+S D(j, k)-G E P_{1}(i) \quad \text { if } j>0, k>0 \\
& H(i, j, k)=\max \left\{\begin{array}{l}
S_{(i-1, j, k)}-G O P_{2}(j, k), \\
H_{(i-1, k, k)}
\end{array}\right\}-G E P_{2}(j, k) \quad \text { if } i>0 \\
& l(i, j, k)=\max \left\{\begin{array}{l}
S_{(i, j-1, k)}-G O P_{2}(i, k), \\
H_{(i, j-1, k)}
\end{array}\right\}-G E P_{2}(i, k) \quad \text { if } j>0 \\
& J(i, j, k)=\max \left\{\begin{array}{l}
S_{(i, j, k-1)}-G O P_{2}(i, j), \\
H_{(i, j, k-1)}
\end{array}\right\}-G E P_{2}(i, j) \quad \text { if } k>0
\end{aligned}
$$

Figure 6 Dynamic programming recursions for three-profile alignment with affine gap costs Scores for the alignment of two residue positions are denoted by $S p(\alpha, \beta)$. The GOP and GEP are gap opening and gap extension penalties, respectively. In affine gap costs, GOP and GEP are fixed values at any residue position.

scores. The best score of the alignments with prefixes $P_{1 i}, P_{2 j}$ and $P_{3 k}$ is denoted by $\mathrm{S}(i, j, k)$ if the residues $\left(P_{1 i}, P_{2 j}, P_{3 k}\right)$ are aligned; $G(i, j, k)$ is the best score given that $\left(P_{1 i}, P_{2 j},-\right)$ is the last column of the partial alignment, and $\mathrm{H}(i, j, k)$ is the best score given that the last column is of the form $\left(P_{1 i},-,-\right) . E(i, j, k), F(i, j, k), I(i, j$, $k)$ and $J(i, j, k)$ are defined analogously. These quantities clearly satisfy the recursions summarized in Fig. 6.

The next step after the alignment is to determine whether amino acid residues critical for imidase activity exist in target and A proteins but are absent in $\sim$ A proteins. In the second step, a voting score (V-score) is given based on the previous assumption, and the Vscores are then summed in each comparison. In this step, a substitution matrix (BLOSUM62) is used to give $\mathrm{V}$-score when each sequence of property $\mathrm{A}$ and $\sim \mathrm{A}$ is compared to the target sequence. The $\mathrm{V}$-score is calculated as follows:

$$
V_{k(a, b)}=M\left[t_{k}, A_{(a, k)}\right]-M\left[t_{k}, \sim A_{(b, k)}\right],
$$

where $V_{k(a, b)}$ is the V-score at the $k$ th residues on target sequence, sequence $a$ in A proteins and sequence $b$ in $\sim \mathrm{A}$ proteins. The A and $\sim \mathrm{A}$ proteins have $m$ and $n$ sequences, respectively. The $t_{k}$ is the $k$ th residue of the 


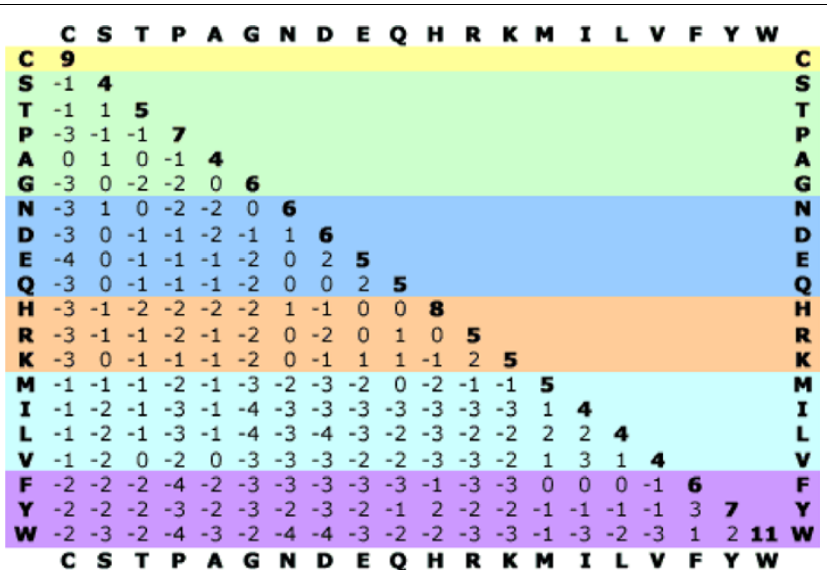

(a)

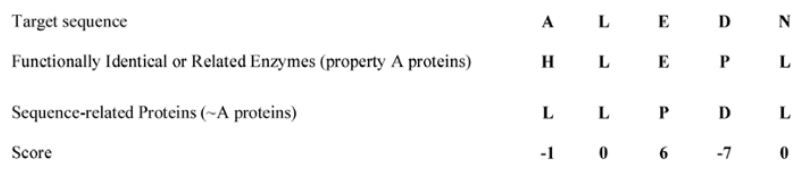

(b)

Figure 7 Score setting and scoring example (a) Substitution matrix for BLOSUM62. In this study, the BLOSUM 62 substitution matrix was used to obtain V-scores for the voting algorithm. (b) Example of FAVAT scoring. When three-profile alignment was performed in the target sequence, the voting scores for A proteins and $\sim A$ proteins corresponded with the BLOSUM62 substitution matrix. For example, residues for target sequence, an A protein and a $\sim A$ protein were A, H and L, respectively. The $\mathrm{V}$-score is -2 (A to H in BLOSUM62) - (-1) (A to L in BLOSUM62) $=-1$.

target sequence. The $A(a, k)$ and $\sim A(b, k)$ are the $k$ th residues on sequence $a$ in A proteins and on sequence $b$ in $\sim$ A proteins, respectively. The $M\left[t_{k}, A_{(a, k)}\right]$ is the value of the substitution matrix for $t_{k}$ and $A_{(a, k)}$. Figure 7 shows the V-score calculation. The BLOSUM62 substitution matrix is generally used for protein or nucleic acid sequence alignment. In the proposed algorithm, each V-score is given and accumulated to a total score
(T-Score) until all sequences of property $\mathrm{A}$ and $\sim \mathrm{A}$ are compared. The T-Score is calculated as follows:

$$
T_{k}=\sum_{a=1}^{m} \sum_{b=1}^{n} \mid V_{k(a, b)},
$$

where $T_{k}$ is the T-Score at the $k$ th residue on target sequence. The $\mathrm{T}$-Score at each residue position is

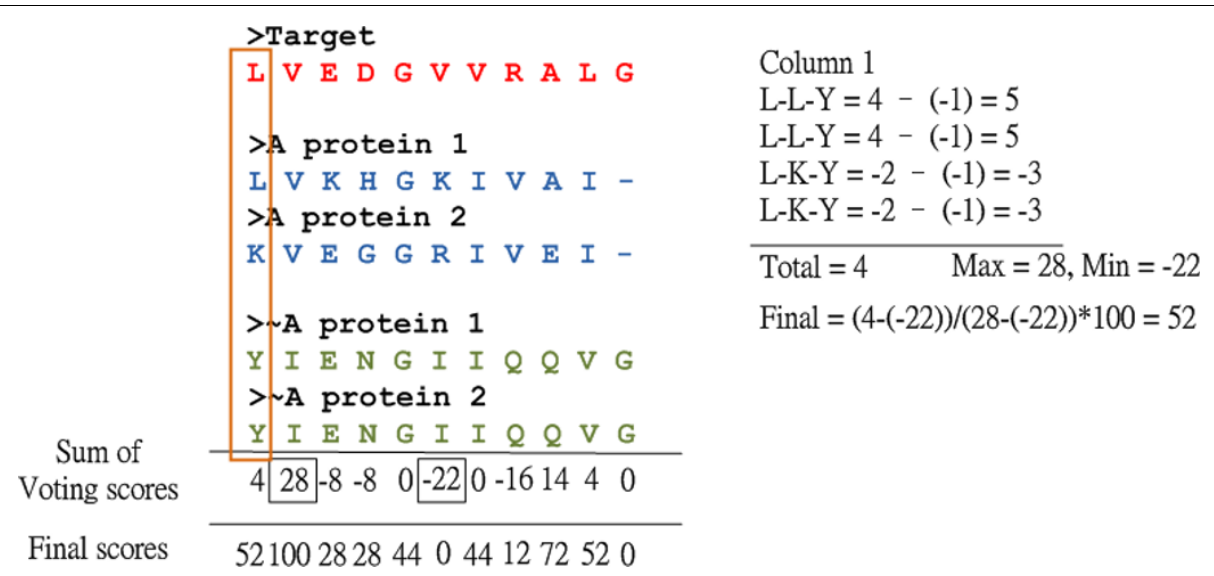

Figure 8 FAVAT scoring example For the first position of the target sequence, four $V$-scores were calculated for $L-L-Y, L-L Y, L-K-Y$ and $L-K-Y$, respectively. The T-score at each position is the sum of four $\mathrm{V}$-scores, and the T-score (total score) for the first position of the target sequence is 4. After the normalization function, the final T-score is 52 . When any gap existed at the position in one of three groups such as column 11 , the T-score for this position is zero. 
obtained by adding $m \times n \mathrm{~V}$-scores. The normalization function is used to transform all $\mathrm{T}$-scores into a range from 0 to 100 in FAVAT. The normalization function is as follows:

$$
T_{k}=\frac{T_{k}-\operatorname{Min}(T)}{\operatorname{Max}(T)-\operatorname{Min}(T)} \times 100,
$$

where $\operatorname{Max}(T)$ and $\operatorname{Min}(T)$ are the maximum and minimum scores of all T-scores, respectively. The details of the FAVAT algorithm are shown below, and Fig. 8 presents an example of V-Score and T-Score calculations using FAVAT.

Algorithm FAVAT ( $t, P, Q)$;

Input: Target sequence $t$, a set of proteins $P$ without property $A$, a set of proteins $Q$ with property $A$. $P$ has $p$ sequences and $Q$ has $q$ sequences.

Ouput: The scores correspond to the residues of $t$ (high $\mathrm{T}$-scores indicate potentially critical residues)

\section{Begin}

1 /"Step1: Do three-profile alignment by dynamic programming method among $t$, the proteins $P$, and the proteins $Q$. The length of the resulting alignments is $m_{\max }$. $t[k]$ indicates the $k$-th residue of $t . * /$

2 fork $<-1$ tom $m_{\max }$ do

3 if $t[k]<>$ ' ' then

4. /*T-score $[k]$ indicates the potential importance of the $k$-th residue of $t$. ${ }^{*} /$

5 T-score $[k]<-0$

$6 \max <--\infty$

$7 \min <-\infty$

8 for $i<-1$ to $p$ do

9 for $j<-1$ to $q$ do

$10 / * X$ and $Y$ are used to store the k-th residue of this $i$-th protein in $P$ and this $j$-th protein in $Q$, respectively. $* /$

$11(X, Y)=(P[i], Q[j], k$-th $)$

12 /"Step 2: Find $V$-score $[k]$ based on the BLOSUM62 substitution matrix."/

13 V-score $[k]<-B L O S U M 62(t[k], Y)$

$14 V$-score $[k]<-V$-score $[k]+(-1) \times$ BLOSUM62 $(t[k], X)$

$15 T$-score $[k]<-T$-score $[k]+V$-score $[k]$

$16 \max <-M A X(\max , T$-score $[k])$

$17 \min <-M I N(\min , T$-score $[k])$

18 end if

19 fork $<-1$ to $m_{\max }$ do

$20 T$-score $[k]=(T$-score $[k]-\min / \max -\min ) \times 100$

/"normalization"/

End

The novel feature of the FAVAT algorithm is its use of the sequence and functional properties among target sequence, $\sim \mathrm{A}$ proteins and A proteins. When voting for reliable critical residue candidates, three relations are considered: the relation between target sequence and $\mathrm{A}$ proteins, the relation between target sequence and $\sim \mathrm{A}$ proteins and the relation between A proteins and $\sim \mathrm{A}$ proteins. To accurately identify the key residues, some useful alignment tools with physicochemical properties, such as T-COFFEE and HMMER, can be employed in the FAVAT pre-process to align A and $\sim$ A proteins separately (profiles). The appropriate alignments of A and $\sim$ A proteins can enhance the accuracy of the resulting alignment to the target sequence, $\mathrm{A}$ and $\sim \mathrm{A}$ proteins by three-profile alignment. The most important residues can then be found accurately from the resulting alignment using FAVAT. The FAVAT algorithm was designed to account for the importance of alignmentbased voting skill by $\mathrm{V}$-score function. The time complexity of FAVAT is $\mathrm{O}\left(\mathrm{m}_{\max }{ }^{3}\right)$, and $\mathrm{m}_{\max }$ is the length of the resulting alignment by three-profile alignment. To reduce the time complexity of three-profile alignment method, this study developed a parallel version implemented by the MPICH library. The time complexity for the parallel version is $\mathrm{O}\left(\mathrm{m}_{\max }{ }^{3} / p\right)$, where $p$ is the number of processors. After the voting process, the residue candidates obtain high T-scores. The uncritical candidates can be eliminated by advanced research.

\section{Acknowledgements}

We would like to thank the anonymous referees for many constructive comments during the revision. We also would like to thank Ted Knoy for editorial assistance. Part of this work was supported by the National Science Council (NSC) under grant NSC98-2218-E-007-005 and NSC97-2221 -E-182-03 3 -MY3. Publication of this supplement was made possible with support from the International Society of Intelligent Biological Medicine (ISIBM). This article has been published as part of BMC Genomics Volume 11 Supplement 3, 2010: The full contents of the supplement are available online at http://www.biomedcentral.com/1471-2164/11?issue=S3.

\section{Author details}

${ }^{1}$ Department of Computer Science, National Tsing Hua University, 101, Section 2 Kuang Fu Road, Hsinchu, Taiwan 300. ${ }^{2}$ Macronix International Co., Ltd., 16, Li-Hsin Road, Science Park, Hsinchu, Taiwan 300. ${ }^{3}$ Department of Computer Science and Information Engineering, Chang Gung University, 259 Wen Hwa 1st Road, Kwei Shan, Taoyuan 333, Taiwan..

\section{Authors' contributions}

$\mathrm{CLH}, \mathrm{CL}$ and CYT conceived the research. CLH and $\mathrm{CL}$ implemented the program and performed the experiments. CLH, CL and CYL arranged the test data and analyzed the experimental results. $\mathrm{CLH}, \mathrm{CL}, \mathrm{CYL}$ and YCC wrote the article. All authors read and approved the final manuscript.

\section{Competing interests}

The authors declare that they have no competing interests.

\section{Published: 1 December 2010}

\section{References}

1. The FAVAT software:[http://sslab.cs.nthu.edu.tw/ allen/favat/index.html].

2. Babbitt PC, Gerlt JA: Understanding enzyme superfamilies. Chemistry As the fundamental determinant in the evolution of new catalytic activities. J Biol Chem 1997, 272:30591-30594.

3. Altschul SF, Gish W, Miller W, Myers EW, Lipman DJ: Basic local alignment search tool. J Mol Biol 1990, 215:403-410.

4. Altschul SF, Boguski MS, Gish W, Wootton JC: Issues in searching molecular sequence databases. Nat Genet 1994, 6:119-129. 
5. Altschul SF, Madden TL, Schaffer AA, Zhang J, Zhang Z, Miller W, Lipman DJ: Gapped BLAST and PSI-BLAST: a new generation of protein database search programs. Nucleic Acids Res 1997, 25:3389-3402.

6. Pearson WR, Lipman DJ: Improved tools for biological sequence comparison. Proc Natl Acad Sci USA 1988, 85:2444-2448.

7. Thompson JD, Higgins DG, Gibson TJ: CLUSTAL W: improving the sensitivity of progressive multiple sequence alignment through sequence weighting, position-specific gap penalties and weight matrix choice. Nucleic Acids Res 1994, 22:4673-4680.

8. Notredame C, Higgins DG, Heringa J: T-Coffee: A novel method for fast and accurate multiple sequence alignment. J Mol Biol 2000, 302:205-217.

9. Edgar RC: MUSCLE: multiple sequence alignment with high accuracy and high throughput. Nucleic Acids Res 2004, 32:1792-1797.

10. Livingstone $C D$, Barton GJ: Protein sequence alignments: a strategy for the hierarchical analysis of residue conservation. Comput Appl Biosci 1993, 9:745-756.

11. Feng DF, Doolittle RF: Progressive sequence alignment as a prerequisite to correct phylogenetic trees. J Mol Evol 1987, 25:351-360.

12. Barton GJ, Sternberg MJ: A strategy for the rapid multiple alignment of protein sequences. Confidence levels from tertiary structure comparisons. J Mol Biol 1987, 198:327-337.

13. Grigoriev IV, Kim SH: Detection of protein fold similarity based on correlation of amino acid properties. Proc Natl Acad Sci USA 1999, 96:14318-14323.

14. Henikoff S, Henikoff JG: Automated assembly of protein blocks for database searching. Nucleic Acids Res 1991, 19:6565-6572.

15. Sonnhammer EL, Kahn D: Modular arrangement of proteins as inferred from analysis of homology. Protein Sci 1994, 3:482-492.

16. Ogiwara A, Uchiyama I, Takagi T, Kanehisa M: Construction and analysis of a profile library characterizing groups of structurally known proteins. Protein Sci 1996, 5:1991-1999.

17. Puntervoll $P$, Linding R, Gemund $C$, Chabanis-Davidson S, Mattingsdal M, Cameron S, Martin DM, Ausiello G, Brannetti B, Costantini A, Ferre F, Maselli V, Via A, Cesareni G, Diella F, Superti-Furga G, Wyrwicz L, Ramu C, McGuigan C, Gudavalli R, Letunic I, Bork P, Rychlewski L, Kuster B, HelmerCitterich $M$, Hunter WN, Aasland R, Gibson TJ: ELM server: A new resource for investigating short functional sites in modular eukaryotic proteins. Nucleic Acids Res 2003, 31:3625-3630.

18. Lichtarge $\mathrm{O}$, Bourne HR, Cohen FE: An evolutionary trace method defines binding surfaces common to protein families. J Mol Biol 1996, 257:342-358.

19. Lichtarge O, Sowa ME, Philippi A: Evolutionary traces of functional surfaces along G protein signaling pathway. Methods Enzymol 2002, 344:536-556.

20. Lichtarge $\mathrm{O}$, Yamamoto KR, Cohen FE: Identification of functional surfaces of the zinc binding domains of intracellular receptors. J Mol Biol 1997, 274:325-337.

21. Innis CA, Shi J, Blundell TL: Evolutionary trace analysis of TGF-beta and related growth factors: implications for site-directed mutagenesis. Protein Eng 2000, 13:839-847.

22. Madabushi S, Gross AK, Philippi A, Meng EC, Wensel TG, Lichtarge O: Evolutionary trace of $\mathrm{G}$ protein-coupled receptors reveals clusters of residues that determine global and class-specific functions. $J \mathrm{Biol}$ Chem 2004, 279:8126-8132

23. King RD, Karwath A, Clare A, Dehaspe L: The utility of different representations of protein sequence for predicting functional class. Bioinformatics 2001, 17:445-454

24. Brudno M, Poliakov A, Salamov A, Cooper GM, Sidow A, Rubin EM, Solovyev V, Batzoglou S, Dubchak I: Automated whole-genome multiple alignment of rat, mouse, and human. Genome Res 2004, 14:685-692.

25. Kolbe D, Taylor J, Elnitski L, Eswara P, Li J, Miller W, Hardison R, Chiaromonte F: Regulatory potential scores from genome-wide threeway alignments of human, mouse, and rat. Genome Res 2004, 14:700-707.

26. Margulies EH, Chen CW, Green ED: Differences between pair-wise and multi-sequence alignment methods affect vertebrate genome comparisons. Trends Genet 2006, 22:187-193.

27. Reyes A, Gissi C, Catzeflis F, Nevo E, Pesole G, Saccone C: Congruent mammalian trees from mitochondrial and nuclear genes using Bayesian methods. Mol Biol Evol 2004, 21:397-403.
28. Murphy WJ, Eizirik E, Johnson WE, Zhang YP, Ryder OA, O'Brien SJ: Molecular phylogenetics and the origins of placental mammals. Nature 2001, 409:614-618

29. Murphy WJ, Eizirik E, O'Brien SJ, Madsen O, Scally M, Douady CJ, Teeling E, Ryder OA, Stanhope MJ, de Jong WW, Springer MS: Resolution of the early placental mammal radiation using Bayesian phylogenetics. Science 2001, 294:2348-2351.

30. Thoden JB, Phillips GN Jr., Neal TM, Raushel FM, Holden HM: Molecular structure of dihydroorotase: a paradigm for catalysis through the use of a binuclear metal center. Biochemistry 2001, 40:6989-6997.

31. Kim GJ, Kim HS: C-terminal regions of D-hydantoinases are nonessential for catalysis, but affect the oligomeric structure. Biochem Biophys Res Commun 1998, 243:96-100.

32. Williams NK, Manthey MK, Hambley TW, O'Donoghue SI, Keegan M, Chapman BE, Christopher son Rl: Catalysis by hamster dihydroorotase: zinc binding, site-directed mutagenesis, and interaction with inhibitors. Biochemistry 1995, 34:11344-11352.

33. Abendroth J, Niefind K, Schomburg D: X-ray structure of a dihydropyrimidinase from Thermus $\mathrm{sp}$. at $1.3 \mathrm{~A}$ resolution. $J \mathrm{Mol} \mathrm{Biol}$ 2002, 320:143-156

34. Deo RC, Schmidt EF, Elhabazi A, Togashi H, Burley SK, Strittmatter SM Structural bases for CRMP function in plexin-dependent semaphorin3A signaling. EMBO J 2004, 23:9-22.

35. Abendroth J, Niefind K, Schomburg D: X-ray structure of a dihydropyrimidinase from Thermus sp. at $1.3 \mathrm{~A}$ resolution. $J \mathrm{Mol} \mathrm{Biol}$ 2002, 320:143-156

36. Copley RR, Bork P: Homology among (betaalpha)(8) barrels: implications for the evolution of metabolic pathways. J Mol Biol 2000, 303:627-641.

37. Gerlt JA, Raushel FM: Evolution of function in (beta/alpha)8-barrel enzymes. Curr Opin Chem Biol 2003, 7:252-264

38. Deo RC, Schmidt EF, Elhabazi A, Togashi H, Burley SK, Strittmatter SM: Structural bases for CRMP function in plexin-dependent semaphorin3A signaling. EMBO J 2004, 23:9-22.

39. Yang YS, Ramaswamy S, Jakoby WB: Rat liver imidase. J Biol Chem 1993 268:10870-10875.

40. Syldatk C, May O, Altenbuchner J, Mattes R, Siemann M: Microbial hydantoinases-industrial enzymes from the origin of life? Appl Microbiol Biotechnol 1999, 51:293-309.

41. Huang CY, Chiang SK, Yang YS, Sun YJ: Crystallization and preliminary Xray diffraction analysis of thermophilic imidase from pig liver. Acta Crystallogr D Biol Crystallogr 2003, 59:943-945.

42. Eadie GS, Bernheim F, Bernheim ML: The partial purification and properties of animal and plant hydantoinases. J Biol Chem 1949 181:449-458.

43. Bernheim F, Bernheim MLC: The hydrolysis of hydantoin by various tissues. J Biol Chem 1946, 163:683-685.

44. Altenbuchner J, Siemann-Herzberg M, Syldatk C: Hydantoinases and related enzymes as biocatalysts for the synthesis of unnatural chiral amino acids. Curr Opin Biotechnol 2001, 12:559-563.

45. Altenbuchner J, Siemann-Herzberg M, Syldatk C: Hydantoinases and related enzymes as biocatalysts for the synthesis of unnatural chiral amino acids. Curr Opin Biotechnol 2001, 12:559-563.

46. Sonnhammer EL, Kahn D: Modular arrangement of proteins as inferred from analysis of homology. Protein Sci 1994, 3:482-492.

47. Wallach DP, Grisolia S: The purification and properties of hydropyrimidine hydrase. J Biol Chem 1957, 226:277-288.

48. Huang CY, Yang YS: Discovery of a novel N-iminylamidase activity: substrate specificity, chemicoselectivity and catalytic mechanism. Protein Expr Purif 2005, 40:203-211.

49. Yang YS, Ramaswamy S, Jakoby WB: Rat liver imidase. J Biol Chem 1993 268:10870-10875.

50. Su TM, Yang YS: Identification, purification, and characterization of a thermophilic imidase from pig liver. Protein Expr Purif 2000, 19:289-297.

51. Huang CY, Yang YS: The role of metal on imide hydrolysis: metal content and $\mathrm{pH}$ profiles of metal ion-replaced mammalian imidase. Biochem Biophy Res Commun 2002, 297:1027-1032.

52. Syldatk C, May O, Altenbuchner J, Mattes R, Siemann M: Microbial hydantoinases - industrial enzymes from the origin of life? Appl Microbiol Biotechnol 1999, 51:293-309. 
53. Hamajima N, Matsuda K, Sakata S, Tamaki N, Sasaki M, Nonaka M: A novel gene family defined by human dihydropyrimidinase and three related proteins with differential tissue distribution. Gene 1996, 180:157-163.

54. Goshima Y, Nakamura F, Strittmatter P, Strittmatter SM: Collapsin-induced growth cone collapse mediated by an intracellular protein related to UNC-33. Nature 1995, 376:509-514.

55. Wang LH, Strittmatter SM: Brain CRMP forms heterotetramers similar to liver dihydropyrimidinase. J Neurochem 1997, 69:2261-2269.

56. Holm L, Sander C: An evolutionary treasure: unification of a broad set of amidohydrolases related to urease. Proteins 1997, 28:72-82.

57. Copley RR, Bork P: Homology among (betaalpha)(8) barrels: implications for the evolution of metabolic pathways. J Mol Biol 2000, 303:627-641.

58. Gerlt JA, Raushel FM: Evolution of function in (beta/alpha)8-barrel enzymes. Curr Opin Chem Biol 2003, 7:252-264.

59. Holm L, Sander C: An evolutionary treasure: unification of a broad set of amidohydrolases related to urease. Proteins 1997, 28:72-82.

60. Wu CH, Huang H, Arminski L, Castro-Alvear J, Chen Y, Hu ZZ, Ledley RS, Lewis KC, Mewes HW, Orcutt BC, Suzek BE, Tsugita A, Vinayaka CR, Yeh LS, Zhang J, Barker WC: The Protein Information Resource: an integrated public resource of functional annotation of proteins. Nucleic Acids Res 2002, 30:35-37.

61. Hamajima N, Matsuda K, Sakata S, Tamaki N, Sasaki M, Nonaka M: A novel gene family defined by human dihydropyrimidinase and three related proteins with differential tissue distribution. Gene 1996, 180:157-163.

62. Sankoff D: Simultaneous solution of the RNA folding, alignment, and protosequence problems. SIAM Journal on Applied Mathematics 1985, 45:810-825.

63. Huang $X$ : Alignment of three sequences in quadratic space. ACM SIGAPP Applied Computing Review 1993, 1:7-12.

64. Eddy SR: Profile hidden Markov models. Bioinformatics 1998, 14:755-763.

65. Henikoff S, Henikoff JG: Amino acid substitution matrices from protein blocks. Proc Natl Acad Sci USA 1992, 89:10915-10919.

66. Kim GJ, Kim HS: C-terminal regions of D-hydantoinases are nonessential for catalysis, but affect the oligomeric structure. Biochem Biophys Res Commun 1998, 243:96-100.

\section{doi:10.1186/1471-2164-11-S3-S14}

Cite this article as: Hung et al:. Feature amplified voting algorithm for functional analysis of protein superfamily. BMC Genomics 201011 (Supp 3):S14.

\section{Submit your next manuscript to BioMed Central and take full advantage of:}

- Convenient online submission

- Thorough peer review

- No space constraints or color figure charges

- Immediate publication on acceptance

- Inclusion in PubMed, CAS, Scopus and Google Scholar

- Research which is freely available for redistribution 